\title{
ЛИЦЕНЗИОННО-РАЗРЕШИТЕЛЬНАЯ ДЕЯТЕЛЬНОСТЬ В СВЕТЕ НОВЫХ КОНСТИТУЦИОННЫХ ПОЛОЖЕНИЙ О ПУБЛИЧНОЙ ВЛАСТИ
}

\author{
Б. Ю. Джамирзе \\ Майкопский государственньй технологический университет \\ Поступила в редакцию 1 июля 2021 г.
}

\begin{abstract}
Аннотация: в 2020 г. была принята поправка к Конституиии РФ, направленная на совершенствование организации и бункиионирования систель публичного управления. Однако введение в Основной закон понятия "публичная власть", закрепленного цельлм рядом норл, породило новые вопросы о систелности публичной власти, ее содержании, способах организации на обозначенных в Конституиии РФ территориях. Актуализировался также вопрос об относимости к систеле публичной власти отдельных субъектов, уполнолоченных осуществлять лицензионно-разрешительную деятельность. В статье фборлулируется вывод о иелесообразности коррекиии федерального законодательства, регулирующего лицензионно-разрешительные и иные управленческие отношения с участиел субъектов квазипубличного управления.

Ключевые слова: лищензионно-разрешительная деятельность, публичная власть, органы исполнительной власти, публичное управление, адлинистративно-правовые режимы, фбедеральные территории.
\end{abstract}

\begin{abstract}
Constitution of the Russian Federation was adopted, aimed at improving the organization and functioning of the public administration system. However, the introduction of the concept of "public power" into the Basic Law, which is fixed by a number of norms, has raised new questions about the system of public power, its content, and methods of organization in the territories designated in the Constitution of the Russian Federation. The issue of the relevance of certain entities authorized to carry out licensing and permitting activities to the system of public power was also updated. The article draws a conclusion about the expediency of correcting the federal legislation regulating licensing and other management relations with the participation of quasi-public management entities.
\end{abstract}

Key words: licensing and licensing activities, public authorities, executive authorities, public administration, administrative and legal regimes, federal territories.

В 2020 г. в Конституцию РФ был введен ряд новых положений, призванных усовершенствовать организацию государственного управления и публичной власти в целом, усилить взаимосвязь органов государственной власти и органов местного самоуправления. Обращает на себя особое внимание легализация понятия «публичная власть», которое ранее в законодательстве не употреблялось. 
В советский период публичная власть рассматривалась в качестве одного из наиболее важных признаков государства. Под ней понималась политическая власть господствующего класса безотносительно к тем или иным формам ее проявления и государственной организации. Ключевыми функциями публичной власти считались подчинение, организация общества и управление им сообразно политическим, экономическим и духовным потребностям данного класса ${ }^{1}$. В результате демократических реформ 1990-х гг. понимание публичной власти трансформировалось под влиянием конституционных преобразований 1993 г., выделивших новый уровень публичного управления - местное самоуправление, органы которого не вошли в систему органов государственной власти. Сообразно әтому система публичной власти рассматривалась и рассматривается многими исследователями в настоящее время как совокупность находящихся во взаимосвязи органов государственной власти (законодательной, исполнительной и судебной) и органов местного самоуправления ${ }^{2}$.

Термин «публичная власть» всегда употреблялся как сугубо доктринальный, на что обращается внимание в последних исследованиях данной тематики ${ }^{3}$. Он имел обобщающий характер, позволяя ученым специалистам в области конституционного и административного права выделять наряду с органами государственной власти и местного самоуправления иных субъектов, на основе законодательно закрепленных полномочий которых можно было судить об их принадлежности к системе публичной власти в связи с осуществляемым ими властно-управленческим воздействием на участников социума.

Теперь же данное понятие отнесено к числу ключевых элементов механизма конституционно-правового регулирования, требующих точного понимания, поскольку от этого зависят эффективная организация и фуннционирование всего аппарата публичного управления со всеми входящими в его систему звеньями.

Вопрос о понимании публичной власти был предметом рассмотрения Конституционного Суда РФ, который единую систему публичной власти считает производной от понятий «государственность» и «государство», что дает понять о приоритете государственной составляющей в указанной системе. В то же время, говоря о едином системном целом в рамках пред194 усмотренных Конституцией РФ конкретных организационных форм, Конституционный Суд РФ называет органы местного самоуправления одним из элементов системы публичной власти политического союза многонационального российского народа ${ }^{4}$.

\footnotetext{
${ }^{1}$ См.: Большая советская энциклопедия. 3-е изд. М., 1975. Т. 21. С. 215.

${ }^{2}$ См.: Советов И. К. Публичная власть в России по Конституции 2020 года // Вестник Прикамского социального ин-та. 2020. № 3 (87). С. 45.

${ }^{3}$ См.: Старилов Ю.Н. Государственное управление в системе единой публичной власти : терминологический итог конституционной редормы // Вестник Воронеж. гос. ун-та. Серия: Право. 2020. № 1. С. 22.

${ }^{4}$ См.: О соответствии положениям глав 1,2 и 9 Конституции Российской Федерации не вступивших в силу положений Закона Российской Федерации о по-
} 
Изложенный подход к пониманию публичной власти направлен на разъяснение положения ч. 3 ст. 132 Конституции РФ о том, что органы государственной власти и органы местного самоуправления образуют единую систему публичной власти в России, осуществляя взаимодействие для наиболее эфрфективного решения задач в интересах проживающего на соответствующей территории населения.

Вместе с тем Основной закон содержит и иные нормы, направленные на организацию публичной власти. Во-первых, введено положение о федеральных территориях, организация публичной власти на которых должна определяться федеральным законом (ч. 1 ст. 67). Во-вторых, как следует из содержания ч. 3 ст. 131 Конституции РФ, федеральным законом могут быть определены особенности реализации публичной власти в территориальных единицах, исчерпывающий перечень которых в Конституции РФ не определен (к ним могут относиться административные центры субъектов РФ, города фредерального значения и иные устанавливаемые федеральным законом территории).

Означают ли данные нормы, что публичная власть на соответствующих территориях должна быть организована на общих началах, т. е. через ее распределение между органами государственной власти и органами местного самоуправления, но с учетом предусмотренных федеральными законами особенностей? На этот вопрос Конституция РФ не дает однозначного ответа, однако законотворческая практика показала возможность иной интерпретации данных конституционных положений. Федеральным законом от 22 декабря 2020 г. № 437-ФЗ (в ред. от 20.04.2021) "О фредеральной территории “Сириус"»" введен особый правовой режим фрункционирования соответствующей федеральной территории, предполагающий создание «органов публичной власти», организуемых и функционирующих на основании названного закона. Они представляют собой симбиоз органов государственной власти и органов местного самоуправления, поскольку, с одной стороны, в них предусмотрены государственные должности и должности государственной гражданской службы (ч. 3 ст. 10), а с другой - через них реализуются полномочия органов местного самоуправления городского округа (ч. 2 ст. 2).

Соответственно, не исключены и иные способы организации публичной власти на федеральных и иных территориях, в которые могут быть заложены и другие подходы, что обусловлено вытекающими из текста Конституции РФ значительными дискреционными полномочиями фредерального законодателя. Однако следует отметить отсутствие должной на-

правке к Конституции Российской Федерации «О совершенствовании регулирования отдельных вопросов организации и функционирования публичной власти», а также о соответствии Конституции Российской Федерации порядка вступления в силу статьи 1 данного Закона в связи с запросом Президента Российской Федерации : заключение Конституционного Суда РФ от 16 марта 2020 г. № 1-3 (п. 7) // Вестник Конституционного Суда РФ. 2020. № 2.

${ }^{5}$ Собр. законодательства Рос. Федерации. 2020. № 52 (ч. 1). Ст. 8583 ; 2021. № 17. Ст. 2877. 
учной проработки как внесения изменений и дополнений в Конституцию РФ относительно вопроса об организации и осуществлении публичной власти, так и последующего практического воплощения отдельных конституционно-правовых норм. Это может привести к системным дефектам законодательства, обнаружение и устранение которых потребует научно обоснованных, комплексных, ресурсоемких и долговременных мер, не ограничиваясь коррекцией отдельных норм ${ }^{6}$.

За конституционно-правовыми положениями об организации системы публичной власти кроется множество вопросов, связанных с возможностью ее осуществления субъектами, не отнесенными к числу органов государственной власти и органов местного самоуправления, с распределением функций и полномочий между «традиционными» органами публичной власти и "новыми», создаваемыми на федеральных территориях, а в перспективе и на иных территориях. Отсутствие научно проработанных вариантов их решения может породить проблемы в сфере определения надлежащих субъектов подзаконного нормотворчества, реализации различных полномочий, присущих органам государственного управления - контрольно-надзорных, регистрационных, аккредитационных, лицензионно-разрешительных.

Термин «публичная власть», получив конституционно-правовое оформление, должен приобрести свойство точности значения, иметь четко понимаемое содержание. В этом смысле характерная для него ранее доктринальность была его преимуществом, что позволяло выявлять формы организации и осуществления публичной власти путем сопоставления их признаков с характерными особенностями функционирования органов государственной власти и органов местного самоуправления. Так, Конституционный Суд РФ еще в 1998 г. установил, что Основным законом не установлен запрет для государства передавать отдельные полномочия органов исполнительной власти негосударственным организациям, вовлеченным в осуществление функций публичной власти, если в этом нет противоречия Конституции РФ и федеральному законодательству ${ }^{7}$.

Если обратиться к лицензионно-разрешительной деятельности, то в научной литературе подчеркивается ее публично-правовой характер, вытекающий из содержания федерального законодательства. Сущность данной деятельности выражается в публично-властном воздействии государства на процесс занятия предпринимательством для предотвращения угроз таким ценностям, как жизнь и здоровье людей, имущество граждан и организаций, окружающая среда. Лицензионно-разрешительная деятельность осуществляется посредством публично-правовых спосо-

${ }^{6}$ См.: Сенякин И. Н., Никитин А. А. Конституционные пределы законотворческого усмотрения // Юридическая наука и практика : Вестник Нижегородской акад. МВД России. 2018. № 1 (41). С. 11.

${ }^{7}$ По делу о проверке конституционности отдельных положений статей 2,12 , 17, 24 и 34 Основ законодательства Российской Федерации о нотариате : постановление Конституционного Суда РФ от 19 мая 1998 г. № 15-П (п. 3) // Собр. законодательства Рос. Федерации. 1998. № 22. Ст. 2491. 
бов и приемов, реализация которых связана с правовой природой органов государственной власти ${ }^{8}$.

Лицензионно-разрешительные процедуры урегулированы рядом фредеральных законодательных актов, значительную роль среди которых играет Федеральный закон от 4 мая 2011 г. № 99-ФЗ (в ред. от 31.07.2020) «О лицензировании отдельных видов деятельности» ${ }^{9}$. Лицензирующими субъектами в большинстве случаев являются органы исполнительной власти федерального и регионального уровней. Ряд видов деятельности подлежат лицензированию Центральным банком РФ (деятельность по проведению организованных торгов, деятельность кредитных организаций, профессиональная деятельность на рынке ценных бумаг, страховая, клиринговая, репозитарная деятельность и др.).

В публично-властном характере лицензионно-разрешительной деятельности органов исполнительной власти и Центрального банка РФ не приходится сомневаться. Принадлежность первых к субъектам публичной власти определяется принципом разделения государственной власти на три ветви, включая исполнительную ветвь власти. Банк России, исходя из смысла ч. 2 ст. 75 Конституции РФ, также отнесен к числу органов государственной власти.

Одновременно законодательством о лицензировании определяются иные варианты организации и осуществления лицензионно-разрешительной деятельности. Во-первых, соответствующими полномочиями наделена Государственная корпорация по космической деятельности «Роскосмос», являющаяся органом управления в области исследования, освоения и использования космического пространства, который правомочен осуществлять фредеральное государственное управление и руководство космической деятельностью ${ }^{10}$. Приведенная законодательная формулировка не проясняет статус указанной корпоращии с точки зрения относимости к системе органов публичной власти, поскольку она не рассматривается как орган государственной власти, а указание на ее государственно-управленческую деятельность не может обусловливать ее отождествление с органом исполнительной власти.

Во-вторых, специфика лицензионно-разрешительного механизма определяется для особых административно-правовых режимов осуществления инновационной, экономической и иной деятельности, обеспечивающих прогрессивное развитие соответствующих отраслей ${ }^{11}$ (режимы

${ }^{8}$ См.: Бабайцева $E$. A. Сходства и различия саморегулирования и лицензирования как средств правового регулирования предпринимательской деятельности // Legal Concept = Правовая парадигма. 2019. T. 18, № 1.

${ }^{9}$ Собр. законодательства Рос. Федерации. 2011. № 19. Ст. 2716 ; 2020. № 31 (ч. 1). Ст. 5029.

${ }^{10} \mathrm{O}$ Государственной корпорации по космической деятельности «Роскосмос» : федер. закон от 13 июля 2015 г. № 215-ФЗ (в ред. от 11.06.2021) (ч. 2 ст. 1) // Собр. законодательства Рос. Федерации. 2015. № 29 (ч. 1). Ст. 4341 ; Рос. газета. 2021. 17 июня.

${ }^{11}$ См.: Административно-правовые режимы в государственном управлении в Российской Федерации : теория и современная практика / под ред. А. Ф. Ноздра- 
инновационного центра «Сколково», международного медицинского кластера, территорий опережающего социально-экономического развития, инновационных научно-технологических центров, свободного порта Владивосток). Подобных территорий довольно много, и их число постепенно увеличивается по ходу выявления законодателем перспектив ускорения экономического роста или инновационного развития тех или иных территорий.

На территории инновационных научно-технологических центров на осуществление образовательной или медицинской деятельности не требуется прохождение процедуры лицензирования в том смысле, в каком это заложено в законодательстве о лицензировании отдельных видов деятельности. Вместо лицензии управляющей компанией выдается разрешение, которое приравнивается к лицензии, выдаваемой при обычной процедуре лицензирования. При этом требования к организациям, претендующим на получение соответствующего разрешения, также устанавливаются управляющей компанией ${ }^{12}$.

Точно такие же правила действуют на территории инновационного центра «Сколково» ${ }^{13}$. В соответствии с положениями соответствующего законодательства управляющей компанией (некоммерческой организацией «Фонд развития Центра разработки и коммерциализации новых технологий») были утверждены Правила осуществления медицинской деятельности на территории инновационного центра «Сколково» ${ }^{14}$, которыми определен собственный разрешительный механизм в сфере здравоохранения. По сути, данный документ по юридической силе равнозначен правительственным актам о лицензировании отдельных видов деятельности. В то же время статус управляющей компании не позволяет отнести ее к органам публичной власти сообразно их конституционному пониманию.

Разъяснения Конституционного Суда РФ о возможности наделения негосударственных субъектов публично-властными полномочиями, характерными для органов исполнительной власти, вряд ли могут считаться актуальными после проведения конституционных преобразований. В сложившихся условиях можно говорить о квазипубличности вышеизло-

198 чева. М., 2017. С. 263-295 ; Лакаев О. А. Правовая политика в сфере организации публичного управления на территориях опережающего социально-экономического развития // Правовая политика и правовая жизнь. 2021. № 1. С. 23-31; Его же. Правовая политика в сфере организации функционирования зон территориального развития // Там же. 2020. № 4. С. 44-52.

${ }^{12}$ Об инновационных научно-технологических центрах и о внесении изменений в отдельные законодательные акты Российской Федерации : федер. закон от 29 июля 2017 г. № 216-Ф3 (в ред. от 30.04.2021) (ст. 21) // Собр. законодательства Рос. Федерации. 2017. № 31 (ч. 1). Ст. 4765 ; 2021. № 18. Ст. 3058.

${ }^{13}$ См.: Об инновационном центре «Сколково» : федер. закон от 28 сентября 2010 г. № 244-ФЗ (в ред. от 02.08.2019) (ст. 17) // Собр. законодательства Рос. Федерации. 2010. № 40. Ст. 4970 ; 2019. № 31. Ст. 4457.

14 Официальный сайт инновационного центра "Сколково». URL: https:// services.sk.ru/service/226 (дата обращения: 24.06.2021). 
женного варианта организации лицензионно-разрешительной деятельности, поскольку, имея основные признаки субъекта публичной власти, управляющая компания официально к таковым не относится.

Думается, что поправка к Конституции РФ, определяющая основы организации и функционирования единой системы публичной власти, была внесена в отсутствие оценки состояния федерального законодательства, определяющего вариативность осуществления различных публично-управленческих полномочий теми или иными юридическими лицами публичного права, в том числе в лицензионно-разрешительной и ряде иных сфрер. Возможным вариантом разрешения возникшей коллизии может стать коррекция фредерального законодательства, регулирующего управленческие отношения с участием субъектов, которые в настоящее время не являются органами публичной власти. Пример федеральной территории «Сириус» показал, что публичная власть может быть организована особым образом, без включения в ее систему органов государственной власти и органов местного самоуправления. Сходным образом может быть оптимизировано и иное законодательство, регулирующее особые административно-правовые режимы осуществления инновационной, экономической и другой деятельности, посредством придания статуса органов публичной власти тем структурам, которые осуществляют управление данными территориями.

\section{Библиографический список}

Административно-правовые режимы в государственном управлении в Российской Федерации : теория и современная практика : монография / под ред. А. Ф. Ноздрачева. М. : Институт законодательства и сравнительного правоведения при Правительстве РФ, 2017. 528 с.

Бабайцева $E$. A. Сходства и различия саморегулирования и лицензирования как средств правового регулирования предпринимательской деятельности // Legal Concept = Правовая парадигма. 2019. Т. 18, № 1. С. 99-104.

Большая советская энциклопедия. 3-е изд. М. : Советская энциклопедия, 1975. T. 21. $640 \mathrm{c.}$

Лакаев О. А. Правовая политика в сфере организации публичного управления на территориях опережающего социально-экономического развития // Правовая политика и правовая жизнь. 2021. № 1. С. 23-31.

Лакаев О. А. Правовая политика в сфере организации фуннкционирования зон территориального развития // Правовая политика и правовая жизнь. 2020. № 4. C. 44-52.

Сенякин И. Н., Никитин А. А. Конституционные пределы законотворческого усмотрения // Юридическая наука и практика : Вестник Нижегородской акад. МВД России. 2018. № 1 (41). С. 10-15.

Советов И. К. Публичная власть в России по Конституции 2020 года // Вестник Прикамского социального ин-та. 2020. № 3 (87). С. 43-52.

Старилов Ю. Н. Государственное управление в системе единой публичной власти : терминологический итог конституционной реформы // Вестник Воронеж. гос. ун-та. Серия: Право. 2020. № 1. С. 20-31. 


\section{References}

Administrative and legal regimes in public administration in the Russian Federation: theory and modern practice: monograph / Ed. by A. F. Nozdrachev. M. : Institute of Legislation and Comparative Law under the Government of the Russian Federation, 2017. 528 p.

Babaytseva E. A. Similarities and differences of self-regulation and licensing as means of legal regulation of entrepreneurial activity // Legal Concept $=$ The legal paradigm. 2019. Vol. 18, № 1. P. 99-104.

The Great Soviet Encyclopedia. 3rd ed. Volume 21. M. : Soviet Encyclopedia, 1975. $640 \mathrm{p}$.

Lakaev O. A. Legal policy in the field of organization of public administration in the territories of advanced socio-economic development // Legal policy and legal life. 2021. № 1. P. 23-31.

Lakaev O. A. Legal policy in the field of organization of functioning of territorial development zones // Legal policy and legal life. 2020. № 4. P. 44-52.

Senyakin I. N., Nikitin A. A. Constitutional limits of legislative discretion // Legal science and practice: Bulletin of the Nizhny Novgorod Academy of the Ministry of Internal Affairs of Russia. 2018. № 1 (41). P. 10-15.

Sovetov I. K. Public power in Russia under the Constitution of 2020 // Bulletin of the Prikamsky Social Institute. 2020. № 3 (87). P. 43-52.

Starilov Yu. N. Public administration in the system of unified public power: terminological result of the constitutional reform // Bulletin of the Voronezh State University. Series: Law. 2020. № 1. P. 20-31.

\section{Для иитирования:}

Джамирзе Б. Ю. Лицензионно-разрешительная деятельность в свете новых конституционных положений о публичной власти // Вестник Воронежского государственного университета. Серия: Право. 2021. № 3 (46). C. 193-200. DOI: https://doi. org/10.17308/vsu.proc.law.2021.3/3550

\section{Recommended citation:}

Dzhamirze B. Yu. Licensing and permitting activities in the light of the new constitutional provisions on public authority // Proceedings of Voronezh State University. Series: Law. 2021. № 3 (46). P. 193-200. DOI: https://doi.org/10.17308/vsu.proc.law.2021.3/3550

Майкопский государственный технологический университет

Джамирзе Б. Ю., кандидат юридических наук, доцент кафбедры административного и уголовного права

E-mail: bella901@mail.ru
Maikop State Technological University

Dzhamirze B. Yu., Candidate of Legal Sciences, Associate Professor of the Administrative and Criminal Law Department E-mail: bella901@mail.ru 